\title{
Determination of primary combustion source organic carbon-to-elemental carbon (OC / EC) ratio using ambient OC and EC measurements: secondary OC-EC correlation minimization method
}

\author{
Cheng $\mathrm{Wu}^{1}$ and Jian Zhen $\mathbf{Y u}^{1,2,3}$ \\ ${ }^{1}$ Division of Environment, Hong Kong University of Science and Technology, Clear Water Bay, Hong Kong, China \\ ${ }^{2}$ Atmospheric Research Centre, Fok Ying Tung Graduate School, Hong Kong University of Science and Technology, \\ Nansha, China \\ ${ }^{3}$ Department of Chemistry, Hong Kong University of Science and Technology, Clear Water Bay, Hong Kong, China \\ Correspondence to: Jian Zhen Yu (jian.yu@ust.hk)
}

Received: 10 December 2015 - Published in Atmos. Chem. Phys. Discuss.: 19 January 2016

Revised: 22 April 2016 - Accepted: 23 April 2016 - Published: 2 May 2016

\begin{abstract}
Elemental carbon (EC) has been widely used as a tracer to track the portion of co-emitted primary organic carbon (OC) and, by extension, to estimate secondary OC (SOC) from ambient observations of EC and OC. Key to this EC tracer method is to determine an appropriate OC / EC ratio that represents primary combustion emission sources (i.e., $\left.(\mathrm{OC} / \mathrm{EC})_{\text {pri }}\right)$ at the observation site. The conventional approaches include regressing $\mathrm{OC}$ against $\mathrm{EC}$ within a fixed percentile of the lowest (OC / EC) ratio data (usually 5$20 \%$ ) or relying on a subset of sampling days with low photochemical activity and dominated by local emissions. The drawback of these approaches is rooted in its empirical nature, i.e., a lack of clear quantitative criteria in the selection of data subsets for the (OC / EC) pri determination. We examine here a method that derives $(\mathrm{OC} / \mathrm{EC})_{\text {pri }}$ through calculating a hypothetical set of $(\mathrm{OC} / \mathrm{EC})_{\text {pri }}$ and SOC followed by seeking the minimum of the coefficient of correlation $\left(R^{2}\right)$ between SOC and EC. The hypothetical (OC/EC) pri that generates the minimum $R^{2}$ (SOC,EC) then represents the actual $(\mathrm{OC} / \mathrm{EC})_{\text {pri }}$ ratio if variations of EC and SOC are independent and (OC / EC) pri is relatively constant in the study period. This Minimum $R$ Squared (MRS) method has a clear quantitative criterion for the (OC/EC) pri calculation. This work uses numerically simulated data to evaluate the accuracy of SOC estimation by the MRS method and to compare with two commonly used methods: minimum OC / EC $\left(\mathrm{OC} / \mathrm{EC}_{\min }\right)$ and $\mathrm{OC} / \mathrm{EC}$ percentile $\left(\mathrm{OC} / \mathrm{EC}_{10} \%\right)$. Log-
\end{abstract}

normally distributed EC and OC concentrations with known proportion of SOC are numerically produced through a pseudorandom number generator. Three scenarios are considered, including a single primary source, two independent primary sources, and two correlated primary sources. The MRS method consistently yields the most accurate SOC estimation. Unbiased SOC estimation by $\mathrm{OC} / \mathrm{EC}_{\min }$ and $\mathrm{OC} / \mathrm{EC}_{10} \%$ only occurs when the left tail of OC / EC distribution is aligned with the peak of the $(\mathrm{OC} / \mathrm{EC})_{\text {pri }}$ distribution, which is fortuitous rather than norm. In contrast, MRS provides an unbiased SOC estimation when measurement uncertainty is small. MRS results are sensitive to the magnitude of measurement uncertainty but the bias would not exceed $23 \%$ if the uncertainty is within $20 \%$.

\section{Introduction}

Organic carbon (OC) and elemental carbon (EC) are among the major components of fine particular matter $\left(\mathrm{PM}_{2.5}\right)$ (Malm et al., 2004). EC is a product of carbon fuel-based combustion processes and is exclusively associated with primary emissions whereas OC can be from both direct emissions and be formed through secondary pathways. Differentiation between primary organic carbon (POC) and secondary organic carbon (SOC) is indispensable for probing at- 
mospheric aging processes of organic aerosols and formulating effective emission control policies. However, direct SOC measurement is not yet feasible, as there lacks knowledge of its chemical composition at the molecular level. Due to its exclusive origin in primary combustion sources, EC was first proposed by Turpin and Huntzicker (1991) to serve as the tracer to track POC from primary combustion sources and, by extension, to estimate SOC as SOC is simply the difference between OC and POC. This EC tracer method only requires measurements of OC and EC. Due to its simplicity, the EC tracer method has been widely adopted in studies reporting ambient OC and EC measurements (e.g., Castro et al., 1999; Cao et al., 2004; Yu et al., 2004). If OC and EC concentrations are available and primary $\mathrm{OC}$ from non-combustion sources $\left(\mathrm{OC}_{\text {non-comb }}\right)$ is negligible, $\mathrm{SOC}$ can be estimated using $\mathrm{EC}$ as the tracer for combustion source POC (Turpin and Huntzicker, 1995):

$\mathrm{POC}=(\mathrm{OC} / \mathrm{EC})_{\mathrm{pri}} \times \mathrm{EC}$

$\mathrm{SOC}=\mathrm{OC}_{\text {total }}-(\mathrm{OC} / \mathrm{EC})_{\text {pri }} \times \mathrm{EC}$

where $(\mathrm{OC} / \mathrm{EC})_{\text {pri }}$ is the $\mathrm{OC} / \mathrm{EC}$ ratio in freshly emitted combustion aerosols, and $\mathrm{OC}_{\text {total }}$ and $\mathrm{EC}$ are available from ambient measurements. Abbreviations used in this study are summarized in Table 1.

The key step in the EC tracer method is to determine an appropriate $\mathrm{OC} / \mathrm{EC}$ ratio that represents primary combustion emission sources (i.e., (OC / EC) $)_{\text {pri }}$ ) at the observation site. Various approaches in deriving $(\mathrm{OC} / \mathrm{EC})_{\text {pri }}$ reported in the literature are either based on emission inventory (Gray et al., 1986) or ambient observation data. Using ambient observation data, three approaches are the most common: (1) regressing measured $\mathrm{OC}$ vs. EC data from times of low photochemical activity and dominated by local emissions; (2) regressing measured OC vs. EC data on a fixed percentile of the lowest OC / EC ratio (usually 5-20\%) data to represent samples dominated by primary emissions (Lim and Turpin, 2002; Lin et al., 2009); and (3) simply taking the minimum OC / EC ratio during the study period to approximate $(\mathrm{OC} / \mathrm{EC})_{\mathrm{pri}}$ (Castro et al., 1999). Combinations of the fixed percentile and the minimum (OC / EC) pri approaches were also used in order to accommodate different sample sizes available. For example, Pio et al. (2011) suggested using the lowest $5 \%$ subset to obtain the (OC / EC) pri , and if the sample size of $5 \%$ subset is less than three, the lowest three data points are used to determine (OC / EC) pri. These approaches have the drawback in that there is not a clear quantitative criterion in the data selection for the (OC / EC) pri determination. Millet et al. (2005) was the first to propose an algorithm that explores the inherent independency between pollutants from primary emissions (e.g., EC) and products of secondary formation processes (e.g., SOC) to derive the primary ratios (e.g., (OC / EC $)_{\text {pri }}$ ) for species with multiple source types. More specifically, for the determination of $(\mathrm{OC} / \mathrm{EC})_{\mathrm{pri}}$, the assumed (OC / EC) pri value is varied continuously. At each hypothetical (OC / EC) pri, SOC is calculated for the data set and a correlation coefficient value $\left(R^{2}\right)$ of EC vs. SOC (i.e., $\left.R^{2}(\mathrm{EC}, \mathrm{SOC})\right)$ is generated. The series of $R^{2}(\mathrm{EC}, \mathrm{SOC})$ values are then plotted against the assumed (OC / EC) pri values. If variations of $\mathrm{EC}$ and $\mathrm{SOC}$ are independent, the assumed $(\mathrm{OC} / \mathrm{EC})_{\text {pri }}$ corresponding to the minimum $R^{2}(\mathrm{EC}, \mathrm{SOC})$ would then represent the actual (OC/EC) pri ratio. Such an approach obviates the need for an arbitrary selection criterion, as the algorithm seeks the minimum point, which is unique to the data set. However, this method has largely been overlooked, with only one study reporting its use (Hu et al., 2012) since its debut, which may be a result of a lack of evaluation of its method performance. Hereafter for the convenience of discussion, we call this method the minimum $R$ squared (MRS) method. An example illustration of the MRS method is shown in Fig. 1. We have developed a computer program in Igor Pro (WaveMetrics, Inc. Lake Oswego, OR, USA) to facilitate MRS calculation and it is available from https://sites.google.com/site/wuchengust.

With ambient OC and EC samples, the accuracy of estimated SOC by different (OC / EC) pri methods is difficult to evaluate due to the lack of a direct SOC measurement. The objective of this study is to investigate, through numerical simulations, the bias of SOC estimates by three different implementations of the EC tracer method. Hypothetic EC, OC, and $(\mathrm{OC} / \mathrm{EC})_{\text {pri }}$ data sets with known break-down of POC and SOC values are numerically synthesized, then SOC is estimated and compared with the "true" SOC as defined by the synthetic data sets. As such, bias of SOC estimates using the various implementations of the EC tracer method can be quantified.

\section{Evaluation of the minimum $R$ squared method}

\subsection{Data generation}

We first examine ambient $\mathrm{OC}$ and EC for the purpose of identifying distribution features that can serve as the reference basis for parameterizing the numerical experiments. The 1year hourly EC and OC measurement data from three sites in the PRD (one suburban site in Guangzhou, a general urban site and a roadside site in Hong Kong, with more than 7000 data at each site), are plotted in Fig. S1 in the Supplement document for the whole year data sets and Figs. S2-S4 for the seasonal subsets using the Nancun site as the example. A brief account of the field ECOC analyzers and their field operation is provided in the Supplement. A detailed description of the measurement results and data interpretation for the sites will be given in a separate paper. The distributions of measured OC, EC and OC / EC are fitted by both normal and log-normal distribution curves and then examined by the Kolmogorov-Smirnov (K-S) test. The $\mathrm{K}-\mathrm{S}$ statistic, $D$, indicates that log-normal fits all three distributions better than the normal distribution ( $D$ values are shown in Figs. S1-S4). 
Table 1. Abbreviations.

\begin{tabular}{|c|c|}
\hline Abbreviation & Definition \\
\hline $\mathrm{EC}$ & elemental carbon \\
\hline $\mathrm{EC}_{1}, \mathrm{EC}_{2}$ & EC from source 1 and source 2 in the two sources scenario \\
\hline$f_{\mathrm{EC} 1}$ & fraction of EC from source 1 to the total EC \\
\hline$f_{\mathrm{SOC}}$ & ratio of SOC to OC \\
\hline MRS & minimum $R$ squared method \\
\hline $\mathrm{MRS}^{\prime}$ & a variant of MRS that use EC from individual sources as input \\
\hline MT & Mersenne twister pseudorandom number generator \\
\hline$n$ & sample size in MT data generation \\
\hline $\mathrm{OC}$ & organic carbon \\
\hline $\mathrm{OC} / \mathrm{EC}$ & $\mathrm{OC}$ to $\mathrm{EC}$ ratio \\
\hline$(\mathrm{OC} / \mathrm{EC})_{\mathrm{pri}}$ & primary OC / EC \\
\hline $\mathrm{OC} / \mathrm{EC}_{10} \%$ & OC / EC at $10 \%$ percentile \\
\hline $\mathrm{OC} / \mathrm{EC}_{\min }$ & minimum OC / EC \\
\hline $\mathrm{OC}_{\text {non-comb }}$ & OC from non-combustion sources \\
\hline PDF & probability density function of a distribution \\
\hline POC & primary organic carbon \\
\hline ROA & ratio of averages \\
\hline RSD & relative standard deviation \\
\hline $\mathrm{RSD}_{\mathrm{EC}}$ & RSD of EC \\
\hline $\mathrm{RSD}_{\mathrm{POC}}$ & RSD of POC \\
\hline $\mathrm{RSD}_{\mathrm{SOC}}$ & RSD of SOC \\
\hline SOC & secondary organic carbon \\
\hline $\mathrm{SOC}_{\mathrm{SvP}}$ & SOC formed from semi-volatile POC \\
\hline$\gamma \_$pri & ratio of the $(\mathrm{OC} / \mathrm{EC})$ pri of source 2 to source 1 \\
\hline$\varepsilon_{\mathrm{EC}}, \varepsilon_{\mathrm{OC}}$ & measurement uncertainty of EC and OC \\
\hline$\gamma$ unc & relative measurement uncertainty \\
\hline$\gamma \_$RSD & the ratio between the RSD values of $(\mathrm{OC} / \mathrm{EC})_{\text {pri }}$ and EC \\
\hline
\end{tabular}

Therefore, log-normal distributions are adopted to define the $\mathrm{OC}, \mathrm{EC}$ and $\mathrm{OC} / \mathrm{EC}$ distributions during data generation in our numerical experiments. Statistics of these ambient OC and EC, along with a few other measurements reported in the literature, are summarized in Table 2 and are considered as the reference for data generation to better represent the real situation.

The probability density function (PDF) for the log-normal distribution of variable $x$ is

$f(x ; \mu, \sigma)=\frac{1}{x \sigma \sqrt{2 \pi}} \times e^{-\frac{(\ln (x)-\mu)^{2}}{2 \sigma^{2}}}$.

The two parameters, $\mu$ and $\sigma$, of the log-normal PDF are related to the average and standard deviation of $x$ through the following equations:

$\mu=\ln (\operatorname{avg})-0.5 \times \ln \left(1+\frac{\mathrm{SD}^{2}}{\mathrm{avg}^{2}}\right)$

$\sigma=\sqrt{\ln \left(1+\frac{\mathrm{SD}^{2}}{\mathrm{avg}^{2}}\right)}$.

First, realistic average and standard deviation values of EC, $(\mathrm{OC} / \mathrm{EC})_{\mathrm{pri}}$, and OC (e.g. Figs. S1-S5) are adopted to cal- culate $\mu$ and $\sigma$. Then the pseudorandom number generator uses $\mu$ and $\sigma$ to synthesize EC and OC data sets.

The Mersenne twister (MT) (Matsumoto and Nishimura, 1998), a pseudorandom number generator, is used in data generation. MT is provided as a function in Igor Pro. The system clock is utilized as the initial condition for generation of pseudorandom numbers. The data generated by MT have a very long period of $2^{19} 937-1$, permitting large data size and ensuring that pseudorandom numbers are statistically independent between each data generation. The latter feature ensures the independent relationship between EC and noncombustion related SOC data. The case with combustionrelated SOC is briefly discussed in Sect. 3. MT also allows assigning a log-normal distribution during pseudorandom number generation to constrain the data. For the verification of the log-normality of MT generated data, a series of $\mathrm{K}-\mathrm{S}$ tests on the generated data for 5000 runs are conducted. As shown in Fig. S6, 94.4\% of runs pass the K$\mathrm{S}$ test. Hence the performance of MT can satisfy the lognormal distributed data generation requirement in this study. In a previous study, Chu (2005) used a variant of sine functions to simulate POC and EC, which limited the data size to 120 , and the frequency distributions of POC and EC exhibited multiple peaks, a characteristic that is not realistic for 


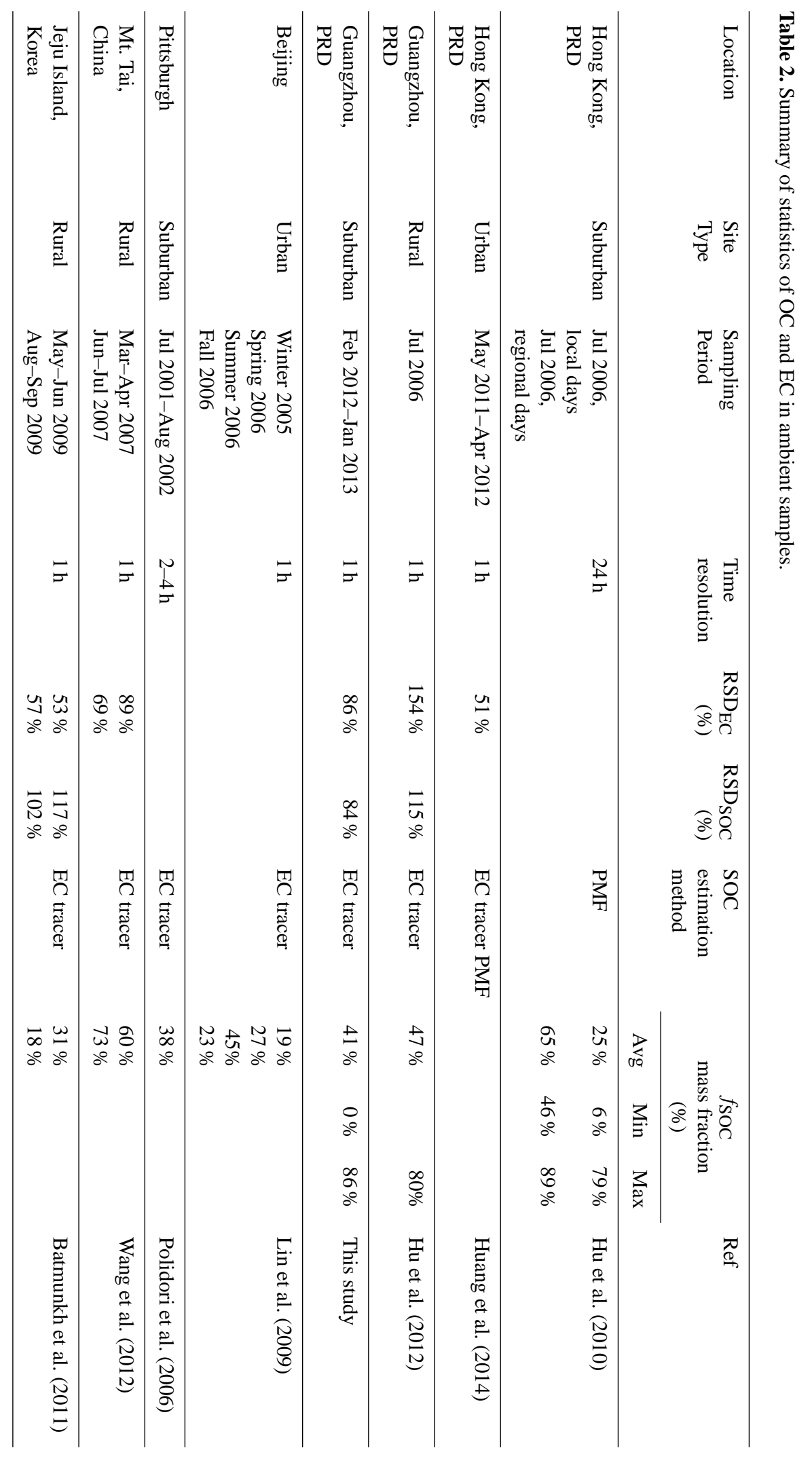




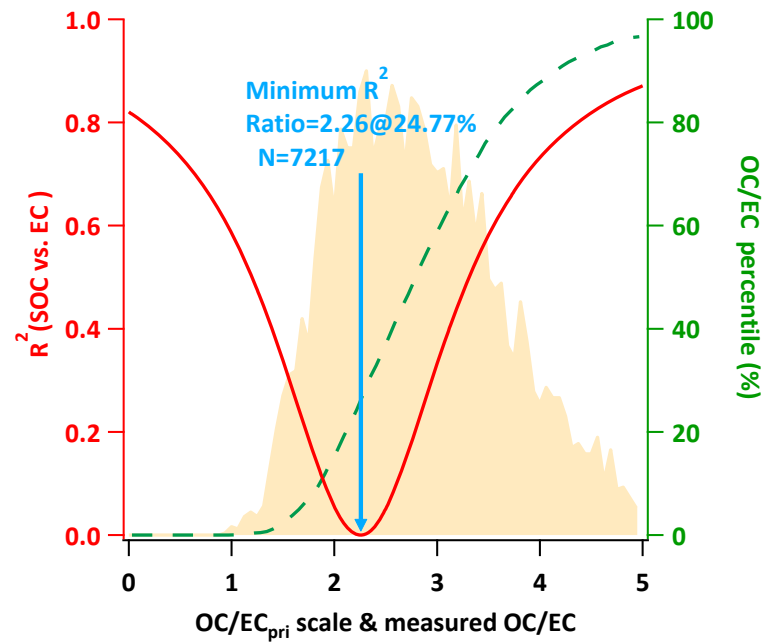

Figure 1. Illustration of the minimum $R$ squared method (MRS) to determine OC / $\mathrm{EC}_{\text {pri }}$ using 1 year of hourly OC and EC measurements at a suburban site in the Pearl River Delta, China. The red curve shows the correlation coefficient $\left(R^{2}\right)$ between SOC and EC as a function of assumed OC / $\mathrm{EC}_{\text {pri }}$. The shaded area in tan represents the frequency distribution of the $\mathrm{OC} / \mathrm{EC}$ ratio for the entire $\mathrm{OC}$ and EC data set. The green dashed curve is the cumulative frequency curve of OC / EC ratio.

ambient measurements. The key information utilized in the $\mathrm{EC}$ tracer method is the correlation between EC and POC as well as the irrelevance between EC and SOC. The time series information is not needed in EC tracer method, making pseudorandom number generator a good fit for the evaluation purpose.

The procedure of data generation for the single emission source scenario is illustrated in Fig. 2 and implemented by scripts written in Igor Pro. EC is first generated with the following parameters specified: sample size $(n)$, average and relative standard deviation (RSD\%) of the whole data set (see Supplement). The EC data set statistically follows a lognormal distribution, while the sequence of each data point is randomly assigned. POC is then calculated by multiplying $\mathrm{EC}$ by $(\mathrm{OC} / \mathrm{EC})_{\text {pri }}$ (Eq. 1). For simplicity, $(\mathrm{OC} / \mathrm{EC})_{\text {pri }}$ is set to be a single value, while an analysis incorporating randomly generated log-normally distributed (OC / EC) pri values can be found in the Supplement, and a brief summary is given in Sect. 2.2. SOC data are independently generated in a similar way to that for EC. The sum of POC and SOC then yields the synthesized OC. OC and EC data generated in this way are used to calculate SOC by different implementations of the EC tracer method. The bias of SOC estimation can then be evaluated by comparing the calculated SOC with the "true" SOC values. Data generation for the scenarios with two primary emission sources is similar to the single source scenario and the steps are illustrated in Fig. S7.

\subsection{Scenario study}

Three scenarios are considered. Scenario 1 (S1) considers one single primary emission source. Scenario 2 (S2) considers two correlated primary emission sources, i.e., two sets of EC, POC, and each source has a single but differ-

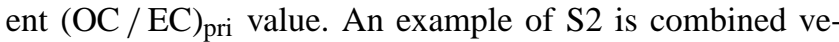
hicular emissions from diesel-fuel and gasoline-fuel vehicles. These two sources of vehicular emissions have different $(\mathrm{OC} / \mathrm{EC})_{\mathrm{pri}}$, but often share a similar temporal variation pattern, making them well correlated. Scenario 3 (S3) considers two independent primary emission sources and simulates an ambient environment influenced by two independent primary emission sources, e.g. local vehicular emissions (lower $\left.(\mathrm{OC} / \mathrm{EC})_{\mathrm{pri}}\right)$ and regional biomass burning (higher $\left.(\mathrm{OC} / \mathrm{EC})_{\text {pri }}\right)$.

In the following numerical experiments, three $(\mathrm{OC} / \mathrm{EC})_{\text {pri }}$ estimation methods are examined and compared, including $\mathrm{MRS}, \mathrm{OC} / \mathrm{EC}_{10} \%$ and $\mathrm{OC} / \mathrm{EC}_{\min }$. $\mathrm{As}$ a single point, $\mathrm{OC} / \mathrm{EC}_{\min }$, in ambient samples may be subjected to large random uncertainties, thus data with the lowest $1 \%$ OC / EC are adopted instead to derive the $\mathrm{OC} / \mathrm{EC}_{\min }$.

\subsubsection{Single primary source scenario}

Both $\mathrm{OC} / \mathrm{EC}_{10} \%$ and $\mathrm{OC} / \mathrm{EC}_{\min }$ methods rely on a subset of ambient $\mathrm{OC}$ and $\mathrm{EC}$ data to approximate $(\mathrm{OC} / \mathrm{EC})_{\text {pri }}$. Figure 3 provides a conceptual illustration of the relationships between (OC / EC) pri and the ambient OC / EC data, both are described to exhibit a log-normal distribution. As primary emissions move away from sources and aging processes start in the atmosphere, SOC is added to the particle OC fraction, elevating OC / EC above (OC / EC) pri. This in effect broadens the OC / EC distribution curve and shifts the distribution to the right along the $\mathrm{OC} / \mathrm{EC}$ axis, and the degree of broadening and shift depends on degree of aging process. The conventional EC tracer method using $\mathrm{OC} / \mathrm{EC}_{10} \%$ and $\mathrm{OC} / \mathrm{EC}_{\min }$ assumes that the left tail of ambient $\mathrm{OC} / \mathrm{EC}$ distribution is very close to $(\mathrm{OC} / \mathrm{EC})_{\text {pri }}$. This assumption, however, is fortuitous, rather than the norm. Two parameters, the distance between the means of the (OC / EC) pri and ambient OC / EC distributions and the relative breadth of the two distributions, largely determines the closeness of the approximation of $\mathrm{OC} / \mathrm{EC}_{10} \%$ and $\mathrm{OC} / \mathrm{EC}_{\min }$ to $(\mathrm{OC} / \mathrm{EC})_{\mathrm{pri}}$. The distance between the two distributions depends on the fraction of SOC in OC (i.e., $f_{\mathrm{SOC}}$ ), while the width of the ambient OC / EC distribution is closely associated with RSD of SOC (RSD SOC $)$ and the width of the $(\mathrm{OC} / \mathrm{EC})_{\text {pri }}$ distribution is reflected in $\mathrm{RSD}_{\mathrm{POC}}$ and $\mathrm{RSD}_{\mathrm{EC}}$. As shown in Fig. 3a, only an appropriate combination of distance of the two distribution means and variances could lead to a close approximation of the $(\mathrm{OC} / \mathrm{EC})_{\mathrm{pri}}$ by $\mathrm{OC} / \mathrm{EC}_{10} \%$ or $\mathrm{OC} / \mathrm{EC}_{\min }$ (i.e., the left tail of $\mathrm{OC} / \mathrm{EC}$ distribution). If the ambient aerosol has a significant $f_{\text {SOC }}$ shifting the ambient OC / EC distri- 


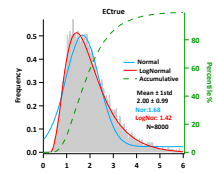

EC

$\mathrm{EC}_{1}$

$\mathrm{EC}_{2}$

$\mathrm{EC}_{3}$

$\underset{\mathrm{EC}_{5}}{\mathrm{EC}_{4}} \times(\mathrm{OC} / \mathrm{EC})_{\mathrm{pri}}$

$\mathrm{EC}_{5}$

$\mathrm{EC}_{6}$

$\mathrm{EC}_{7}$

$\mathrm{EC}_{\mathrm{n}}$
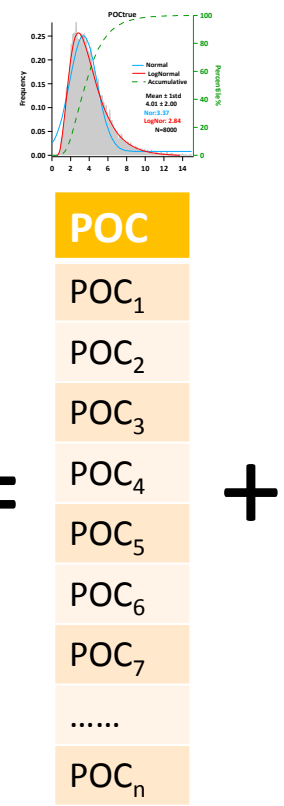
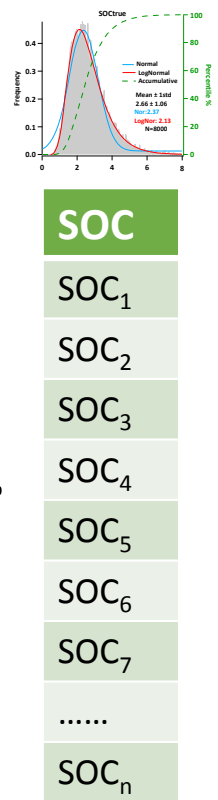
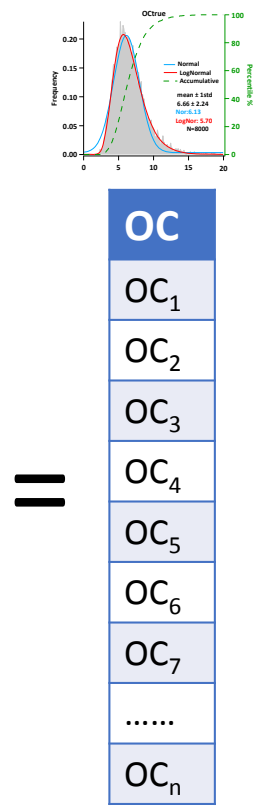

Figure 2. Schematic diagram of pseudorandom number generation for the single emission source scenario that assumes (OC / EC) pri is a single value. The data series (EC and SOC), generated by Mersenne twister (MT) pseudorandom number generator, statistically follow a log-normal distribution, but the sequence of each data point is randomly assigned.

bution such that its left tail is beyond (OC / EC) pri (Fig. 3b), then the left tail would overestimate (OC / EC) pri. Underestimation of (OC / EC) pri could also happen in theory as shown in Fig. 3c if the ambient minimum OC / EC (left tail) is less than the mean of the $(\mathrm{OC} / \mathrm{EC})_{\text {pri }}$ distribution (i.e., under conditions of very small $\left.f_{\mathrm{SOC}}\right)$.

The above analysis reveals that $f_{\mathrm{SOC}}, \mathrm{RSD}_{\mathrm{SOC}}, \mathrm{RSD}_{\mathrm{POC}}$, and $\mathrm{RSD}_{\mathrm{EC}}$ are key parameters in influencing the accuracy of SOC estimation. As a result, they are chosen in the subsequent sensitivity tests in probing the SOC estimate bias under conditions of different carbonaceous aerosol compositions.

SOC estimation bias in $\mathrm{S} 1$ as a function of $\mathrm{RSD}_{\mathrm{SOC}}$ and $\mathrm{RSD}_{\mathrm{EC}}$ is shown in Fig. $4 \mathrm{a}$ and $\mathrm{b}$. The SOC estimate by MRS is not affected by the magnitude of $\mathrm{RSD}_{\mathrm{EC}}$ and $\mathrm{RSD}_{\mathrm{SOC}}$, and is in excellent agreement with the true values (Fig. 4). In comparison, $\mathrm{SOC}$ by $\mathrm{OC} / \mathrm{EC}_{10} \%$ and $\mathrm{OC} / \mathrm{EC}_{\min }$ is consistently biased lower and the degree of negative bias becomes larger with decreasing $\mathrm{RSD}_{\mathrm{SOC}}$ or $\mathrm{RSD}_{\mathrm{EC}}$. The $\mathrm{OC} / \mathrm{EC}_{10} \%$ method always produces larger negative bias than the OC $/ \mathrm{EC}_{\min }$ method. At $\mathrm{RSD}_{\mathrm{SOC}}$ and $\mathrm{RSD}_{\mathrm{EC}}$ at $50 \%$, SOC estimate has a $-14 \%$ bias by $(\mathrm{OC} / \mathrm{EC})_{\min }$ and $\mathrm{a}-45 \%$ bias by $\mathrm{OC} / \mathrm{EC}_{10} \%$. These results confirm the hypothesis illustrated in the conceptual diagram (Fig. 3) that the validity of using the left tail of OC / EC distribution depends on the distance of its distribution mean from $(\mathrm{OC} / \mathrm{EC})_{\text {pri }}$ and the distribution breadth. Both $\mathrm{OC} / \mathrm{EC}_{10} \%$ and the $\mathrm{OC} / \mathrm{EC}_{\min }$ methods underestimate $\mathrm{SOC}$ and the degree of underestimation by the $\mathrm{OC} / \mathrm{EC}_{10} \%$ method is worse.
For the representation of $(\mathrm{OC} / \mathrm{EC})_{\text {pri }}$ in the simulated data as lognormally distributed data, analysis is also performed to evaluate SOC estimation bias as a function of $\mathrm{RSD}_{\mathrm{EC}}, \mathrm{RSD}_{\mathrm{SOC}}$, and $f_{\mathrm{SOC}}$. Table S2 summarizes the results obtained with adopting most probable ambient conditions (i.e., $\mathrm{RSD}_{\mathrm{EC}}: 50-100 \%$, $f_{\mathrm{SOC}}: 40-60 \%$ ). SOC bias by MRS is within $4 \%$ when measurement uncertainty is ignored. In comparison, $\mathrm{SOC}$ bias by $\mathrm{OC} / \mathrm{EC}_{\min }$ is more sensitive to assumption of log-normally distributed (OC / EC) pri than single value (OC / EC) pri , including the dependency on $\mathrm{RSD}_{\mathrm{EC}}$ and $\mathrm{RSD}_{\mathrm{SOC}}$ with varied $f_{\mathrm{SOC}}$.

\subsubsection{Scenarios assuming two primary sources}

In the real atmosphere, multiple combustion sources impacting a site is normal. We next evaluate the performance of the MRS method in scenarios of two primary sources and arbitrarily dictate that the $(\mathrm{OC} / \mathrm{EC})_{\text {pri }}$ of source 1 is lower than source 2 . By varying $f_{\mathrm{EC} 1}$ (proportion of source $1 \mathrm{EC}$ to total EC) from test to test, the effect of different mixing ratios of the two sources can be examined. Common configurations in $\mathrm{S} 2$ and S3 include the following: $\mathrm{EC}_{\text {total }}=2 \pm 0.4 \mu \mathrm{gC} \mathrm{m}{ }^{-3}$; $f_{\mathrm{EC} 1}$ varies from 0 to $100 \%$; ratio of the two $\mathrm{OC} / \mathrm{EC}_{\text {pri }}$ values ( $\gamma \_$pri) vary in the range of $2-8$.

In Scenario 2 (i.e., two correlated primary sources), three factors are examined, including $f_{\mathrm{EC} 1}, \gamma_{-}$pri and $f_{\mathrm{SOC}}$, to probe their effects on SOC estimation. By varying $f_{\mathrm{EC} 1}$, the effect of different mixing ratios of two sources can be examined, as $f_{\mathrm{EC} 1}$ is expected to vary within the same ambient data set as a result of spatiotemporal dynamics 

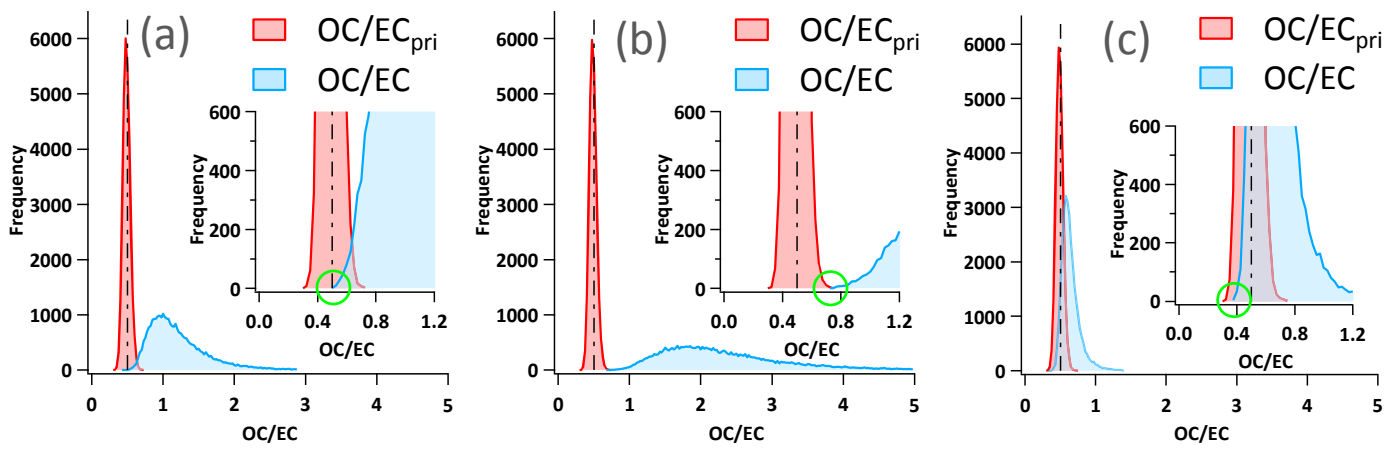

Figure 3. Conceptual diagram illustrating three scenarios of the relationship between (OC / EC $)_{\text {pri }}$ and ambient OC / EC measurements. Both are assumed to be log-normally distributed. (a) Ambient minimum (left tail) is equal to the peak of (OC / EC) pri. (b) Ambient minimum OC / EC (left tail) is larger than the mean of (OC / EC) pri. (c) Ambient minimum OC / EC (left tail) is less than the peak of (OC / EC) pri.
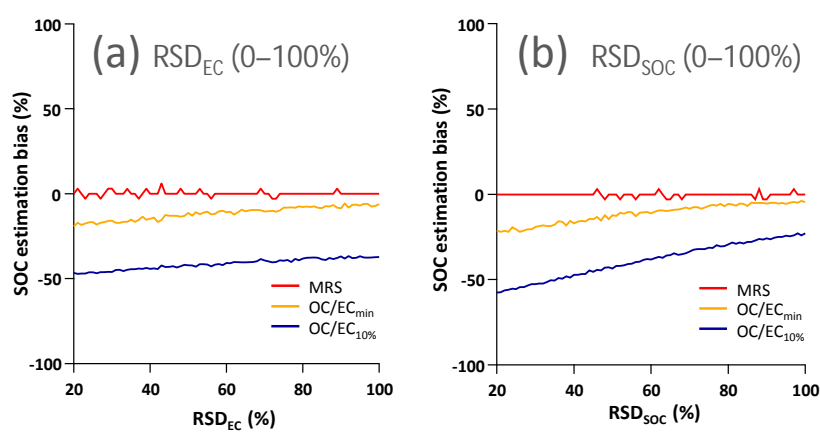

Figure 4. Bias of SOC determination as a function of (a) $\operatorname{RSD}_{\mathrm{EC}}$; (b) $\mathrm{RSD}_{\mathrm{SOC}}$. Different representation of $(\mathrm{OC} / \mathrm{EC})_{\text {pri }}$ include MRS, OC $/ \mathrm{EC}_{\min }$ and $\mathrm{OC} / \mathrm{EC}_{10} \%$. Fixed input parameters: $n=8000, \quad \mathrm{EC}=2 \pm 1 \mu \mathrm{gC} \mathrm{m}{ }^{-3},(\mathrm{OC} / \mathrm{EC})_{\mathrm{pri}}=0.5, \quad \mathrm{POC}=1 \pm$ $0.5 \mu \mathrm{gC} \mathrm{m}{ }^{-3}, f_{\mathrm{SOC}}=40 \%$, and $\mathrm{SOC}=0.67 \pm 0.34 \mu \mathrm{gC} \mathrm{m}{ }^{-3}$.

of air masses. MRS reports unbiased SOC, irrespective of different $f_{\mathrm{EC} 1}$ and $f_{\mathrm{SOC}}$ or $\gamma_{\text {_pri }}$ (Fig. 5). In comparison, SOC by $\mathrm{OC} / \mathrm{EC}_{10} \%$ and $\mathrm{OC} / \mathrm{EC}_{\min }$ are underestimated. The degree of underestimation depends on $f_{\text {SOC }}$, e.g., $-12 \%$ at $f_{\mathrm{SOC}}=25 \%$ versus $-20 \%$ at $f_{\mathrm{SOC}}=40 \%$ in the $\mathrm{OC} / \mathrm{EC}_{\min }$ method while the magnitude of underestimation has a very weak dependence on $f_{\mathrm{SOC}}$ in the $\mathrm{OC} / \mathrm{EC}_{10} \%$ method, staying around $-40 \%$ as $f_{\text {SOC }}$ is doubled from 20 to $40 \%$. The degree of SOC bias by $\mathrm{OC} / \mathrm{EC}_{10} \%$ and $\mathrm{OC} / \mathrm{EC}_{\min }$ are independent of $f_{\mathrm{EC} 1}$ and $\gamma_{-}$pri, as SOC bias is associated with $\mathrm{RSD}_{\mathrm{EC}}, \mathrm{RSD}_{\mathrm{SOC}}$ and $f_{\mathrm{SOC}}$. Since two primary sources are well correlated, $\mathrm{RSD}_{\mathrm{EC}}$ is equivalent between the two sources. As a result, the overall $\mathrm{RSD}_{\mathrm{EC}}$ is con-

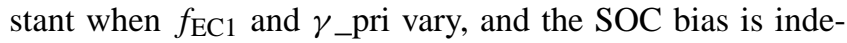
pendent of $f_{\mathrm{EC} 1}$ and $\gamma_{-}$pri.

In summary, in scenarios of two well-correlated primary combustion sources, MRS always produces unbiased SOC estimates while $\mathrm{OC} / \mathrm{EC}_{\min }$ and $\mathrm{OC} / \mathrm{EC}_{10} \%$ consistently underestimate $\mathrm{SOC}$, with $\mathrm{OC} / \mathrm{EC}_{10} \%$ producing larger negative bias.
As for Scenario 3 in which two independent primary sources co-exist, SOC estimates by MRS could be biased and the degree and direction of bias depends on $f_{\mathrm{EC} 1}$. Figure 6a shows the variation of SOC bias with $f_{\mathrm{EC} 1}$ when $f_{\mathrm{SOC}}$ is fixed at $40 \%$. The variation of SOC bias by MRS with $f_{\mathrm{EC} 1}$ follows a pseudo-sine curve, exhibiting negative bias when $f_{\mathrm{EC} 1}<50 \%$ (i.e., $\mathrm{EC}$ is dominated by source 2, the higher $(\mathrm{OC} / \mathrm{EC})_{\text {pri }}$ source) and positive bias when $f_{\mathrm{EC} 1}>50 \%$ and the range of bias are confined to -20 to $-40 \%$ under the condition of $f_{\mathrm{SOC}}=40 \%$. In comparison, the $\mathrm{OC} / \mathrm{EC}_{\mathrm{min}}$ and $\mathrm{OC} / \mathrm{EC}_{10} \%$ methods again consistently underestimate SOC by more than $-50 \%$, with the bias worsened in the $\mathrm{OC} / \mathrm{EC}_{10} \%$ method.

The bias variation range becomes narrower with increasing $f_{\mathrm{SOC}}$ in the MRS method, as shown by the boxplots for four $f_{\text {SOC }}$ conditions $(20,40,60$, and $80 \%)$ in Fig. 6 b. The MRS-derived SOC bias range is reduced from -20 to $+40 \%$ at $f_{\mathrm{SOC}}=40 \%$ to -10 to $+20 \%$ at $f_{\mathrm{SOC}}=60 \%$, further to -6 to $+10 \%$ at $f_{\mathrm{SOC}}=80 \%$. In the other two methods, the SOC bias does not improve with increasing $f_{\mathrm{SOC}}$. Dependence of the SOC estimation bias on $\gamma \_$pri is examined in Fig. $6 \mathrm{c}$ showing the higher $\gamma_{-}$pri induces a higher amplitude of the SOC bias. If OC is dominated by SOC (e.g., $f_{\mathrm{SOC}}=80 \%$ ), SOC bias by MRS is within $10 \%$.

A variant of MRS implementation (denoted as MRS') is examined, with the important difference that $\mathrm{EC}_{1}$ and $\mathrm{EC}_{2}$, attributed to source 1 and source 2, respectively, are used as inputs instead of total EC. With the knowledge of EC breakdown between the two primary sources, $(\mathrm{OC} / \mathrm{EC})_{\text {pril }}$ can be determined by MRS from $\mathrm{EC}_{1}$ and $\mathrm{OC}_{\text {total }}$. Similarly (OC / EC) pri2 can be calculated by MRS from $\mathrm{EC}_{2}$ and $\mathrm{OC}_{\text {total }}$. $\mathrm{SOC}$ is then calculated with the following equation:

$$
\begin{aligned}
\mathrm{SOC} & =\mathrm{OC}_{\text {total }}-(\mathrm{OC} / \mathrm{EC})_{\mathrm{pri} 1} \times \mathrm{EC}_{1} \\
& -(\mathrm{OC} / \mathrm{EC})_{\mathrm{pri} 2} \times \mathrm{EC}_{2} .
\end{aligned}
$$

MRS $^{\prime}$ produces unbiased SOC, irrespective of the different carbonaceous compositions (Fig. 6). However, we note that 

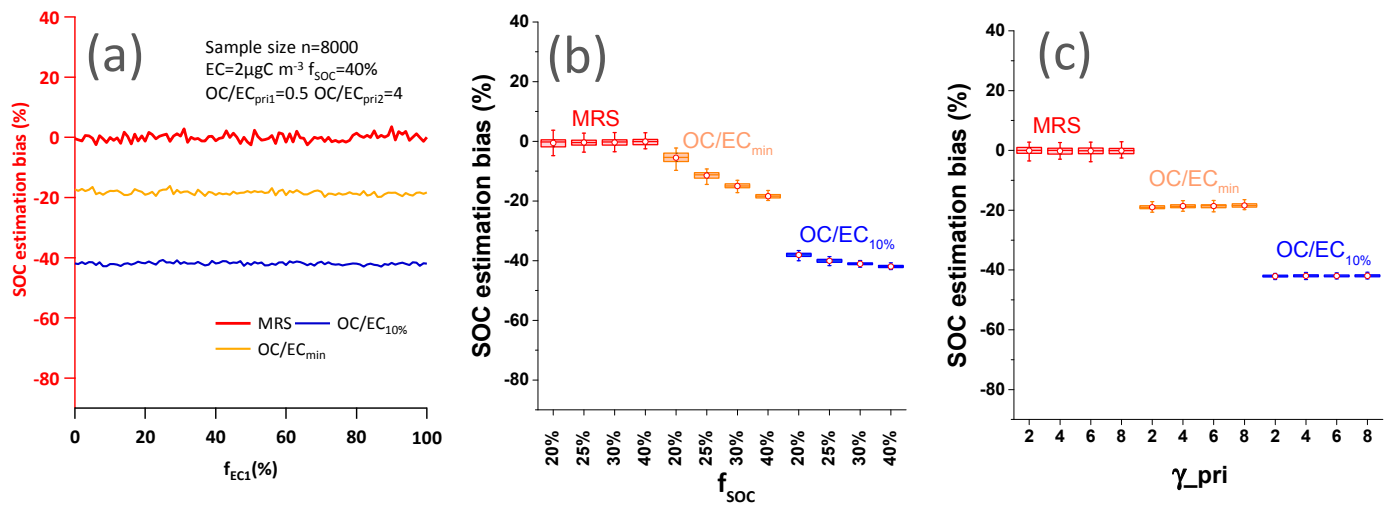

Figure 5. SOC bias in Scenario 2 (two correlated primary emission sources of different (OC / EC) pri) as estimated by four different EC tracer methods denoted in red, blue and yellow. (a) SOC bias as a function of $f_{\mathrm{EC} 1}$. Results shown here are calculated using $f_{\mathrm{SOC}}=40 \%$ as an example. (b) Range of SOC bias shown in boxplots for four $f_{\mathrm{SOC}}$ conditions $(20,25,30$ and $40 \%$ ). (c) Range of SOC bias shown in boxplots for four $\gamma \_$pri conditions (2, 4, 6 and 8). The symbols in the boxplots are empty circles for average, the line inside the box for median, the box boundaries representing the 75 th and the 25 th percentile, and the whiskers representing the 95 th and 5 th percentile.
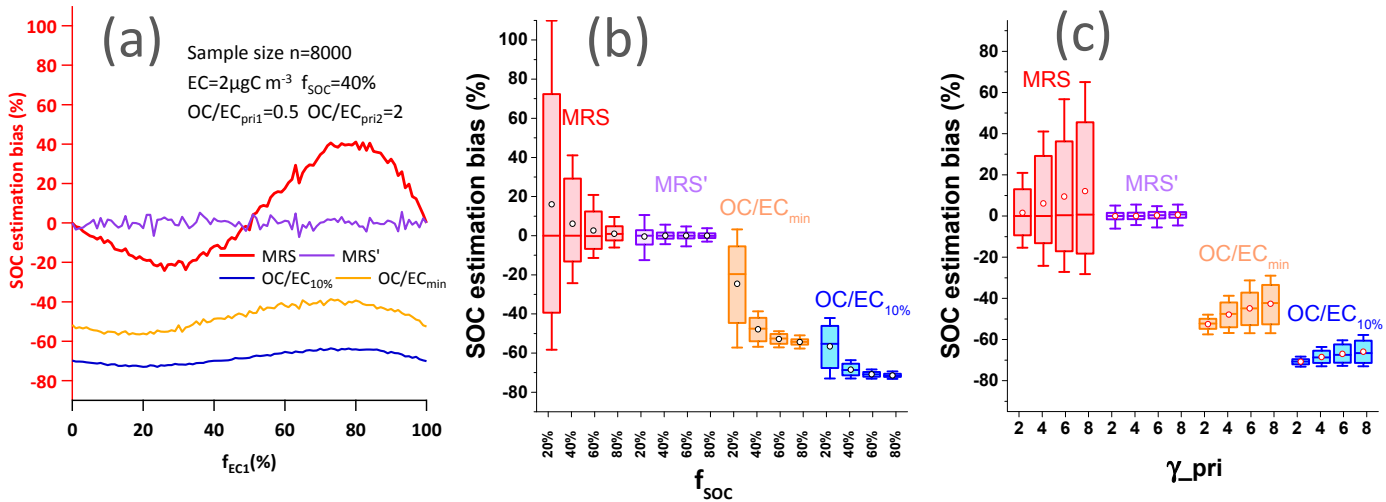

Figure 6. SOC bias in Scenario 3 (two independent primary emission sources of different (OC / EC)pri) as estimated by four different EC tracer methods denoted in red, purple, yellow and blue. MRS ${ }^{\prime}$ differs from MRS in that $\mathrm{EC}_{1}$ and $\mathrm{EC}_{2}$ instead of total EC are used as inputs. (a) SOC bias as a function of $f_{\mathrm{EC} 1}$. Results shown here are calculated using $f_{\mathrm{SOC}}=40 \%$ and $\gamma \_$pri $=4$ as an example. (b) Range of SOC bias shown in boxplots for four $f_{\text {SOC }}$ conditions $\left(20,40,60\right.$ and $80 \%$ ). (c) Range of SOC bias shown in boxplots for four $\gamma \_$pri conditions (2, 4, 6 and 8 ). The symbols in the boxplots are empty circles as average, the line inside the box as median, upper and lower boundaries of the box representing the 75 th and the 25 th percentile, and the whiskers above and below each box representing the 95 th and 5th percentile.

there is a great challenge in meeting the data needs of $\mathrm{MRS}^{\prime}$ as $\mathrm{EC}_{1}$ and $\mathrm{EC}_{2}$ are not available.

In scenario 3, the simulation results imply that three factors are associated with the SOC bias by MRS, including: $f_{\mathrm{EC} 1}, \gamma_{-}$pri and $f_{\mathrm{SOC}}$. The first factor controls whether SOC bias by MRS is positive or negative. The latter two affect the degree of SOC bias. For high $f_{\text {SOC }}$ conditions, the bias could be acceptable. If $\mathrm{EC}_{1}$ and $\mathrm{EC}_{2}$ can be differentiated for calculating individual (OC / EC) $)_{\text {pri }}$ of each source, unbiased SOC estimation is achievable regardless of what values $f_{\mathrm{EC} 1}$, $\gamma \_$pri and $f_{\text {SOC }}$ take.

\subsection{Impact of measurement uncertainty}

In the preceding numerical analysis, the simulated EC and $\mathrm{OC}$ are not assigned any measurement uncertainty; however, in reality, every EC and OC measurement is associated with a certain degree of measurement uncertainty. We next examine the influence of OC and EC measurement uncertainty on SOC estimation accuracy by different EC tracer methods. Two uncertainty types are tested, i.e., constant relative uncertainty (Case A); constant absolute uncertainty (Case B). This section mainly focuses on sensitivity tests assuming different degrees of Case A uncertainties. Results assuming Case B uncertainties are discussed in the next section. The uncertainties are assumed to follow a uniform distribution and generated separately by MT. It is also assumed that the uncertainty $\left(\varepsilon_{\mathrm{EC}}\right.$ or $\left.\varepsilon_{\mathrm{OC}}\right)$ is proportional to the concentration of $\mathrm{EC}$ and OC through the multiplier $\gamma_{\text {unc }}$ (i.e., relative measurement uncertainty). 

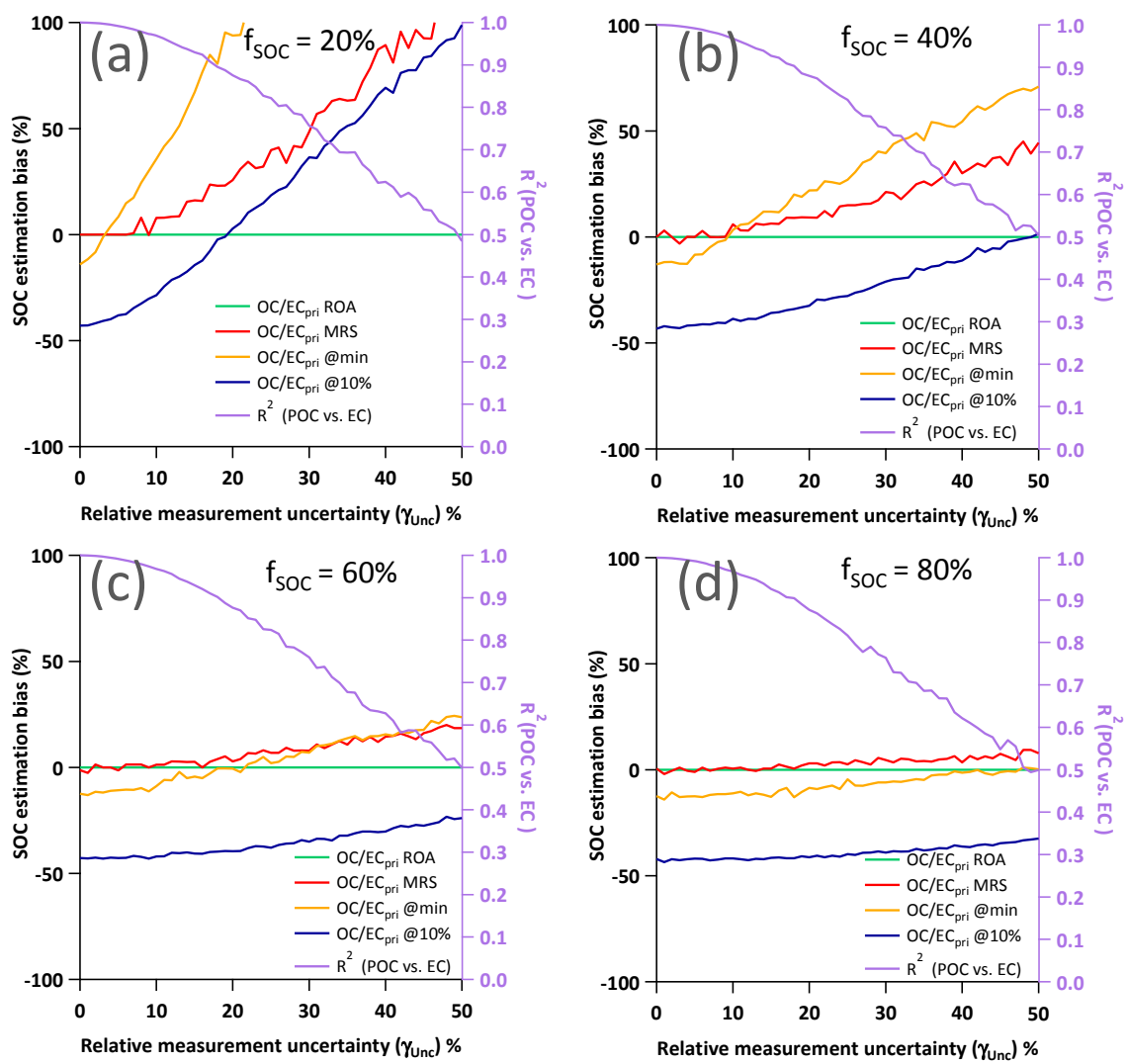

Figure 7. Bias of SOC determination as a function of relative measurement uncertainty $\left(\gamma_{\mathrm{unc}}\right)$ and SOC / OC ratio $\left(f_{\mathrm{SOC}}\right)$ by different approaches of estimating $(\mathrm{OC} / \mathrm{EC})_{\text {pri }}$, including ratio of averages (ROA), minimum $R$ squared (MRS), $\mathrm{OC} / \mathrm{EC}_{10} \%$, and $\mathrm{OC} / \mathrm{EC}_{\min }$. Fixed input parameters: $n=8000, \mathrm{EC}=2 \pm 1 \mu \mathrm{gC} \mathrm{m}{ }^{-3},(\mathrm{OC} / \mathrm{EC})_{\text {pri }}=0.5$. Variable input parameters: (a) $f_{\mathrm{SOC}}=20 \%$, SOC $=0.25 \pm$ $0.13 \mu \mathrm{gC} \mathrm{m}{ }^{-3}$, (b) $f_{\mathrm{SOC}}=40 \%$, SOC $=0.67 \pm 0.33 \mu \mathrm{gC} \mathrm{m}{ }^{-3}$, (c) $f_{\mathrm{SOC}}=60 \%, \mathrm{SOC}=1.5 \pm 0.75 \mu \mathrm{gCm}^{-3}$, and (d) $f_{\mathrm{SOC}}=80 \%$, $\mathrm{SOC}=4 \pm 2 \mu \mathrm{gC} \mathrm{m}{ }^{-3}$.

$-\gamma_{\mathrm{unc}} \mathrm{EC} \leq \varepsilon_{\mathrm{EC}} \leq \gamma_{\mathrm{unc}} \mathrm{EC}$

$-\gamma_{\mathrm{unc}} \mathrm{OC} \leq \varepsilon_{\mathrm{OC}} \leq \gamma_{\mathrm{unc}} \mathrm{OC}$

In order to compare the estimated SOC with simulated SOC with $\varepsilon_{\mathrm{SOC}}$, the measurement uncertainties of POC and SOC are then back-calculated following the uncertainty propagation formula and assuming the same relative measurement uncertainty for POC and SOC (Harris, 2010)

$$
\begin{aligned}
& \gamma_{\mathrm{unc}}^{\prime}=\gamma_{\mathrm{unc}} \sqrt{\frac{\mathrm{OC}^{2}}{\mathrm{POC}^{2}+\mathrm{SOC}^{2}}} \\
& -\gamma_{\mathrm{unc}}^{\prime} \mathrm{POC} \leq \varepsilon_{\mathrm{POC}} \leq \gamma_{\mathrm{unc}}^{\prime} \mathrm{POC} \\
& -\gamma_{\mathrm{unc}}^{\prime} \mathrm{SOC} \leq \varepsilon_{\mathrm{SOC}} \leq \gamma_{\mathrm{unc}}^{\prime} \mathrm{SOC} .
\end{aligned}
$$

The simulated EC, POC and SOC with measurement uncertainties (abbreviated as $\mathrm{EC}_{\text {simulated, }} \mathrm{POC}_{\text {simulated }}$ and $\mathrm{SOC}_{\text {simulated }}$ respectively) are determined as

$$
\begin{aligned}
& \mathrm{EC}_{\text {simulated }}=\mathrm{EC}_{\text {true }}+\varepsilon_{\mathrm{EC}} \\
& \mathrm{POC}_{\text {simulated }}=\mathrm{POC}_{\text {true }}+\varepsilon_{\mathrm{POC}} \\
& \mathrm{SOC}_{\text {simulated }}=\mathrm{SOC}_{\text {true }}+\varepsilon_{\mathrm{SOC}} .
\end{aligned}
$$

Sensitivity tests of SOC estimation as a function of relative measurement uncertainty $\left(\gamma_{\mathrm{unc}}\right)$ and $f_{\mathrm{SOC}}$ is performed as shown in Fig. 7 by comparing the estimated $\mathrm{SOC}$ with $\mathrm{SOC}_{\text {simulated. }}$ Fixed input parameters include $n=$ 8000; $\mathrm{EC}=2 \pm 1 \mu \mathrm{gC} \mathrm{m}^{-3}$; $(\mathrm{OC} / \mathrm{EC})_{\mathrm{pri}}=0.5$. Studies by Chu (2005) and Saylor et al. (2006) suggest that ratio of average POC to average EC (ROA, see Supplement for details) is the best estimator of the expected primary $\mathrm{OC} / \mathrm{EC}$ ratio because it is mathematically equivalent to the true regression slope when the data contain no intercept. ROA is confirmed as the best representation of (OC / EC) pri for SOC estimation, which shows no bias towards $\gamma_{\text {unc }}$ or $f_{\text {SOC }}$ change. MRS overestimates SOC and the positive bias increases with $\gamma_{\text {unc }}$ while decreasing with $f_{\text {SOC }}$ (Fig. 7). The SOC estimates by $\mathrm{OC} / \mathrm{EC}_{\min }$ and $\mathrm{OC} / \mathrm{EC}_{10} \%$ exhibit larger bias than those by MRS. For example, as shown in Fig. 7a, 
when $f_{\mathrm{SOC}}=20 \%$ and $\gamma_{\mathrm{unc}}=10 \%$, the bias of SOC by MRS, $\mathrm{OC} / \mathrm{EC}_{10} \%$ and $\mathrm{OC} / \mathrm{EC}_{\min }$ is $8,-28$ and $36 \%$, respectively. With increasing $f_{\mathrm{SOC}}$, the bias of SOC by $\mathrm{OC} / \mathrm{EC}_{\mathrm{min}}$ decreases while the bias of SOC by $\mathrm{OC} / \mathrm{EC}_{10} \%$ increases when $\gamma_{\text {unc }}=10-20 \%$. MRS always demonstrates the best performance in SOC determination amongst the three (OC / EC) pri estimation methods. When $\gamma_{\text {unc }}$ could be controlled within $20 \%$, the SOC bias by MRS does not exceed $23 \%$ when $f_{\text {SOC }}=20 \%$ (Fig. 7a). If the $f_{\text {SOC }}$ ratio falls in the range of $60-80 \%$ and $\gamma_{\text {unc }}$ is $<20 \%$, the $\mathrm{OC} / \mathrm{EC}_{\min }$ has a similar performance as MRS, but SOC by OC / $\mathrm{EC}_{10} \%$ still shows a large bias ( $\sim 1 \%$ ) (Fig. $7 \mathrm{c}$ and d).

Sensitivity studies of SOC estimation as a function of $\gamma_{\text {unc }}$ and $(\mathrm{OC} / \mathrm{EC})_{\text {pri }}$ are performed and the results are shown in Fig. S8. In all the three (OC / EC) pri representations, SOC estimates are sensitive to $\gamma_{\text {unc }}$ but insensitive to the magnitude of (OC / EC) $)_{\text {pri }}$. In the single primary source scenario (S1), it is proved that the performance of MRS regarding SOC estimation is mainly affected by $\gamma_{\text {unc }}$ and to a lesser degree by $f_{\text {SOC. }}$. Other variables such as (OC / EC) $)_{\text {pri }}$ and EC concentration do not affect the accuracy of SOC estimation.

\subsection{Impact of sample size}

MRS relies on correlations of input variables and it is expected that MRS performance is sensitive to the sample size of input data set. This section examines the sensitivity on sample size by the three $(\mathrm{OC} / \mathrm{EC})_{\text {pri }}$ representations and aims to provide suggestions for an appropriate sample size when applying MRS on ambient OCEC data. Sample sizes ranging from 20 to 8000 are tested and for each sample size 500 repeat runs are conducted to obtain statistically significant results. Both Case A (i.e., a constant relative uncertainty of $10 \%$ ) and Case B (i.e., a constant absolute uncertainty of $\pm 0.2 \mu \mathrm{gC} \mathrm{m}^{-3}$ for both OC and EC) are considered. The measurement uncertainties in case $\mathrm{B}$ are generated separately by MT following a uniform distribution within the range of $\pm 0.2 \mu \mathrm{gC} \mathrm{m}{ }^{-3}$. The measurement uncertainties of POC and SOC are then back-calculated following the uncertainty propagation formula (Harris, 2010) and assuming the ratio of $\varepsilon_{\mathrm{POC}} / \varepsilon_{\mathrm{SOC}}$ is the same as POC / SOC ratio (controlled by $f_{\mathrm{SOC}}$ ).

The mean SOC bias by MRS is very small $(<3 \%)$ for all sample sizes while the standard deviation of SOC bias decreases with sample size (Fig. 8). The standard deviation of SOC bias is $\sim \pm 30 \%$ at the lowest test sample size $(n=20)$, and decreases to less than $\pm 15 \%$ at $n=60$ (the sample size of 1-year sampling from an every-6-day sampling program) and to less than $\pm 10 \%$ at $n=200$. Similar patterns are observed between Case A (Fig. 8a) and Case B (Fig. 8b) for MRS and $\mathrm{OC} / \mathrm{EC}_{10} \%$. For $\mathrm{OC} / \mathrm{EC}_{\min }$, a larger bias is observed in Case B than Case A for all sample sizes, as SOC bias by $\mathrm{OC} / \mathrm{EC}_{\min }$ is more sensitive to measurement uncertainty in the range of $0-10 \%$ as shown in Fig. $7 \mathrm{~b}$. The standard deviation of SOC bias by $\mathrm{OC} / \mathrm{EC}_{\min }$ and $\mathrm{OC} / \mathrm{EC}_{10} \%$
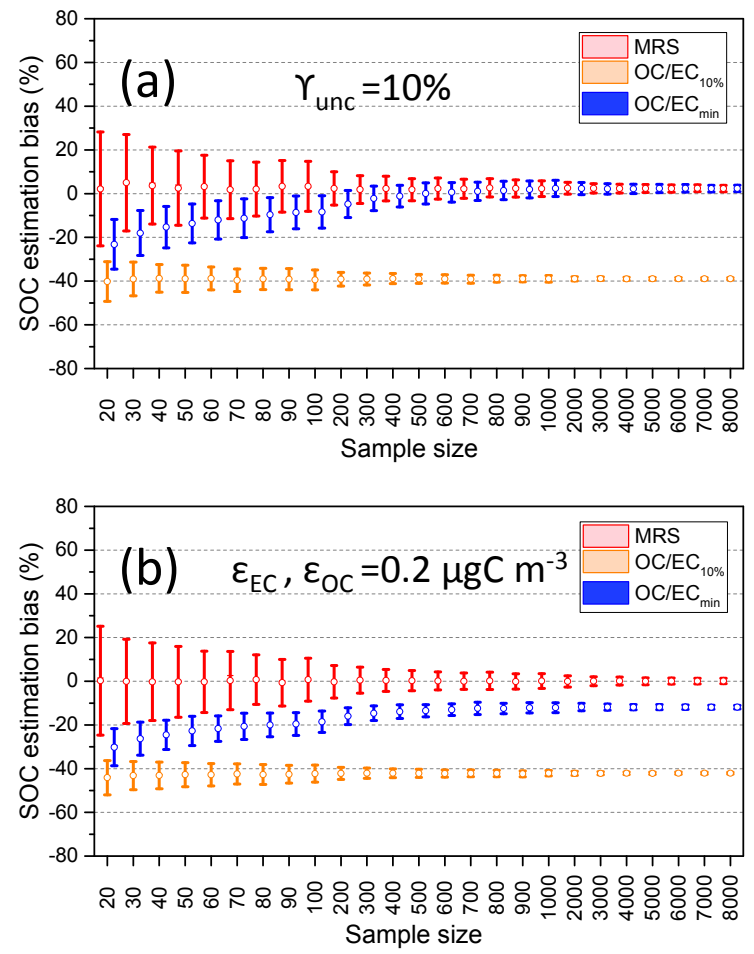

Figure 8. SOC estimation bias as a function of sample size by different approaches of estimating (OC / EC) pri, including minimum $R$ squared (MRS), $\mathrm{OC} / \mathrm{EC}_{10} \%$, and $\mathrm{OC} / \mathrm{EC}_{\min }$, (a) assuming a fixed relative measurement uncertainty of $10 \%$ for OC and EC; (b) assuming a fixed absolute measurement uncertainty for OC and EC $\left(0.2 \mu \mathrm{g} \mathrm{m}^{-3}\right)$. For each sample size, 500 repeat runs were conducted. The empty circles represent mean of 500 repeat runs, the whiskers represent 1 standard deviation. Parameters used for testing: repeat runs $=500, n=20-8000, \mathrm{EC}=8 \pm$ $4 \mathrm{\mu gC} \mathrm{m}^{-3}, \quad(\mathrm{OC} / \mathrm{EC})_{\mathrm{pri}}=0.5, \quad \mathrm{POC}=4 \pm 2 \mu \mathrm{gC} \mathrm{m}{ }^{-3}, f_{\mathrm{SOC}}=$ $40 \%$, and $\mathrm{SOC}=2.67 \pm 1.33 \mu \mathrm{gC} \mathrm{m}^{-3}$.

both decrease with sample size as shown in Fig. 8. The mean SOC bias of OC / $\mathrm{EC}_{\min }$ decrease with increased sample size while $\mathrm{OC} / \mathrm{EC}_{10} \%$ is insensitive to sample size. The sample size dependency of all three $(\mathrm{OC} / \mathrm{EC})_{\text {pri }}$ representations is not sensitive to $f_{\mathrm{SOC}}$ as shown in Fig. S16. Other scenarios considering (OC / EC) pri with a distribution and different $f_{\mathrm{SOC}}$ are discussed in the Supplement.

\subsection{Impact of sampling time resolution}

Besides hourly measurements of OC and EC by online aerosol carbon analyzers, the MRS method could also be applied to offline measurements of OC and EC based on filters collected over longer durations (i.e., $24 \mathrm{~h}$ ), which are more readily available around the world. To explore the impact of sampling duration (e.g., hourly vs. daily), we here use 1-year hourly data at the suburban site of Guangzhou to average them into longer intervals of $2-24 \mathrm{~h}$. The $24 \mathrm{~h}$ averaged samples yield a (OC / EC) $)_{\text {pri }}$ of $2.53,12 \%$ higher than 
Table 3. Summary of numerical study results under different scenarios ${ }^{\mathrm{a}}$.

\begin{tabular}{|c|c|c|c|c|c|}
\hline & \multirow[t]{2}{*}{ Tested parameter } & \multicolumn{4}{|c|}{ SOC bias } \\
\hline & & $\mathrm{MRS}^{\mathrm{b}}$ & $\mathrm{MRS}^{\prime \mathrm{c}}$ & $\mathrm{OC} / \mathrm{EC}_{\min }$ & $\mathrm{OC} / \mathrm{EC}_{10} \%$ \\
\hline & $\mathrm{RSD}_{\mathrm{EC}}$ & $\pm 4 \%$ & & -13 to $-7 \%$ & -43 to $-36 \%$ \\
\hline \multirow{2}{*}{ Single source } & $\mathrm{RSD}_{\mathrm{SOC}}$ & $\pm 4 \%$ & & -11 to $-4 \%$ & -42 to $-22 \%$ \\
\hline & $\gamma_{\text {unc }}$ & $+10 \%$ & & -12 to $20 \%$ & -43 to $-32 \%$ \\
\hline \multirow{3}{*}{$\begin{array}{l}\text { Scenario } 2 \\
\text { Two correlated } \\
\text { sources }\end{array}$} & $f_{\mathrm{EC} 1}$ & $\pm 4 \%$ & & $-20 \%$ & $-40 \%$ \\
\hline & $\gamma \_$pri & $\pm 4 \%$ & & $-20 \%$ & $-40 \%$ \\
\hline & $f_{\mathrm{SOC}}$ & $\pm 4 \%$ & & $-20 \%$ & $-40 \%$ \\
\hline \multirow{3}{*}{$\begin{array}{l}\text { Scenario } 3 \\
\text { Two independent } \\
\text { sources }\end{array}$} & $f_{\mathrm{EC} 1}$ & -20 to $40 \%$ & $\pm 10 \%$ & $-50 \%$ & $-60 \%$ \\
\hline & $\gamma \_$pri & -20 to $40 \%$ & $\pm 10 \%$ & $-50 \%$ & $-60 \%$ \\
\hline & $f_{\mathrm{SOC}}$ & -20 to $40 \%$ & $\pm 10 \%$ & $-50 \%$ & $-60 \%$ \\
\hline
\end{tabular}

the (OC / EC) pri derived from hourly data (2.26). This comes as a result of that $\mathrm{OC} / \mathrm{EC}$ distributions are narrowed when the averaging interval lengthens (Fig. 9), leading to elevation of the MRS-derived (OC / EC) pri. As many $\mathrm{PM}_{2.5}$ speciation networks adopt a sampling schedule of one $24 \mathrm{~h}$ sample every 6 days, we further extract the every-6-day samples to do the MRS calculation. The 1-year data yield six subsets of daily samples, corresponding to six possible schedules of sampling days with the every-6-day sampling frequency. The MRS calculation produces the $\mathrm{OC} / \mathrm{EC}_{\text {pri }}$ in the range of 2.37-2.75 (5-22\% higher than the OC / $\mathrm{EC}_{\mathrm{pri}}$ from the hourly data). This example illustrates that if $24 \mathrm{~h}$ sample ECOC data are used, SOC would be biased slightly lower in comparison with those derived from the hourly data.

\section{Caveats of the MRS method in its applications to ambient data}

Table 3 summarizes the performance in terms of SOC estimation bias by the different implementations of the EC tracer method, assuming typical variation characteristics for ambient ECOC data. When employing the EC tracer method on ambient samples, it is clear that MRS is preferred since it can provide more accurate SOC estimation.

If the sampling site is dominated by a single primary source (similar to Scenario 1), MRS can perform much better than the traditional OC / EC percentile and minimum approaches. Two issues should be paid attention to when applying MRS: (1) MRS relies on the independence of EC and SOC. This assumption could be invalid if a fraction of SOC is formed from semi-volatile POC (here referred as $\mathrm{SOC}_{\mathrm{svP}}$ ) (Robinson et al., 2007). Since POC is well correlated with $\mathrm{EC}$, this $\mathrm{SOC}_{\mathrm{svP}}$ would be attributed to POC by MRS, causing SOC underestimation. The interference of $\mathrm{SOC}_{\mathrm{svP}}$ will be discussed in a separate paper. (2) $\mathrm{OC}_{\text {non-comb }}$ will be at-

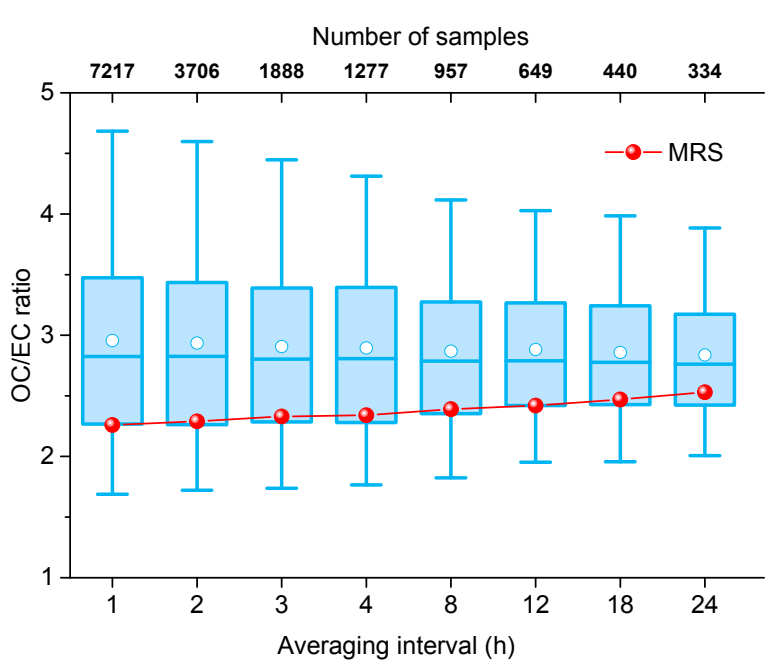

Figure 9. OC / EC distributions assuming different average intervals from 2 to $24 \mathrm{~h}$ and the corresponding MRS-derived OC / $\mathrm{EC}_{\text {pri }}$. The bottom $x$ axis represents averaging interval (e.g. $1 \mathrm{~h}$ is the original data time resolution, $2 \mathrm{~h}$ referring average $1 \mathrm{~h}$ data into $2 \mathrm{~h}$ interval data, etc.). The top $x$ axis represents the number of data point corresponding to the respective data averaging interval. Distributions of OC / EC ratio at various averaging intervals are shown as box plots (empty circles: average, the line inside the box: median, the box boundaries: 75 th and the 25 th percentile, and the whiskers: 95th and 5th percentile). The red dots represent calculated (OC / EC) pri by MRS.

tributed to SOC if only EC is used as a tracer. If $\mathrm{OC}_{\text {non-comb }}$ is small compared to SOC, such approximation is acceptable. Otherwise quantification of its contribution is needed. If a stable tracer for $\mathrm{OC}_{\text {non-comb }}$ is available, determination of $\mathrm{OC}_{\text {non-comb }}$ contribution by MRS is possible, since this scenario is mathematically equivalent to $\mathrm{S} 3$ (e.g., relabel EC2 to tracer of $\mathrm{OC}_{\text {non-comb }}$ and $\mathrm{POC}$ to $\mathrm{OC}_{\text {non-comb }}$ ). 
If the sampling site is influenced by two correlated primary sources with distinct (OC / EC) pri (Scenario 2, e.g. urban areas that have vehicular emission from both gasoline and diesel), MRS is still much more reliable than the traditional OC / EC percentile and minimum approaches. If the sampling site is influenced by two independent primary sources with distinct (OC / EC) pri (Scenario 3, e.g. vehicular emission and biomass burning), SOC estimation by MRS is better than the other two conventional methods. But it should be noted that possible bias may exist and the magnitude of bias depends on the relative abundance between the two sources. If tracers are available to demarcate the EC contributions by the different primary sources, unbiased SOC estimation is possible by employing these tracers in MRS.

\section{Conclusions}

In this study, the accuracy of SOC estimation by EC tracer method is evaluated by comparing three (OC/EC) pri determination approaches using numerically simulated data. The MRS method has a clear quantitative criterion for the $(\mathrm{OC} / \mathrm{EC})_{\text {pri }}$ calculation, while the other two commonly used methods, namely minimum $\mathrm{OC} / \mathrm{EC}\left(\mathrm{OC} / \mathrm{EC}_{\min }\right)$ and $\mathrm{OC} / \mathrm{EC}$ percentile (e.g. $\mathrm{OC} / \mathrm{EC}_{10} \%$ ), are empirical in nature. Three scenarios are considered in the numerical simulations to evaluate the SOC estimation bias by the different EC tracer methods assuming typical variation characteristics for ambient ECOC data. In the scenarios of a single primary source and two well-correlated primary combustion sources, SOC estimates by MRS are unbiased while $\mathrm{OC} / \mathrm{EC}_{\min }$ and $\mathrm{OC} / \mathrm{EC}_{10} \%$ consistently underestimate SOC when measurement uncertainty is neglected. When measurement uncertainty is considered, all three approaches produce biased SOC estimates, with MRS producing the smallest bias. The bias by MRS does not exceed $23 \%$ when measurement uncertainty is within $20 \%$ and $f_{\text {SOC }}$ is not lower than $20 \%$. In the scenario of two independent primary sources, SOC by MRS exhibit bias but still perform better than $\mathrm{OC} / \mathrm{EC}_{\min }$ and $\mathrm{OC} / \mathrm{EC}_{10} \%$. If EC from each independent source can be differentiated to allow calculation of individual (OC / EC) $)_{\mathrm{pri}}$ for each source, unbiased SOC estimation is achievable. Sensitivity tests of OC and EC measurement uncertainty on SOC estimation demonstrate the superior accuracy of MRS over the other two approaches.

Sensitivity tests show that MRS produces mean SOC values with a very small bias for all sample sizes while the precision worsens as the sample size decreases. For a data set with a sample size of 60 , SOC bias by MRS is $2 \pm 15 \%$. When the sample is 200 , the results by MRS are improved to $2 \pm 8 \%$. It is clear that when employing the EC tracer method to estimate SOC, MRS is preferred over the two conventional methods (OC / $\mathrm{EC}_{10} \%$ and $\mathrm{OC} / \mathrm{EC}_{\min }$ ) since it can provide more accurate SOC estimation. We also evaluated the impact of longer sampling duration on derived (OC / EC) pri and found that if $24 \mathrm{~h}$ sample ECOC data are used, SOC would be biased slightly lower in comparison with those derived from the hourly data.

\section{The Supplement related to this article is available online at doi:10.5194/acp-16-5453-2016-supplement.}

Acknowledgements. This work is supported by the National Science Foundation of China (21177031), and the Fok Ying Tung Graduate School (NRC06/07.SC01). The authors thank Hong Kong Environmental Protection Department for making available the ECOC data at Tsuen Wan and Dui Wu of Institute of Tropical and Marine Meteorology, China Meteorological Administration for providing logistic support of OC EC measurements in Nancun. The authors are also grateful to Stephen M. Griffith for the helpful comments.

Edited by: A. Sorooshian

\section{References}

Batmunkh, T., Kim, Y. J., Lee, K. Y., Cayetano, M. G., Jung, J. S., Kim, S. Y., Kim, K. C., Lee, S. J., Kim, J. S., Chang, L. S., and An, J. Y.: Time-Resolved Measurements of $\mathrm{PM}_{2.5}$ Carbonaceous Aerosols at Gosan, Korea, J. Air Waste Manage., 61, 1174-1182, 2011.

Cao, J. J., Lee, S. C., Ho, K. F., Zou, S. C., Fung, K., Li, Y., Watson, J. G., and Chow, J. C.: Spatial and seasonal variations of atmospheric organic carbon and elemental carbon in Pearl River Delta Region, China, Atmos. Environ., 38, 4447-4456, doi:10.1016/j.atmosenv.2004.05.016, 2004.

Castro, L. M., Pio, C. A., Harrison, R. M., and Smith, D. J. T.: Carbonaceous aerosol in urban and rural European atmospheres: estimation of secondary organic carbon concentrations, Atmos. Environ., 33, 2771-2781, 1999.

Chu, S. H.: Stable estimate of primary OC / EC ratios in the EC tracer method, Atmos. Environ., 39, 1383-1392, 2005.

Gray, H. A., Cass, G. R., Huntzicker, J. J., Heyerdahl, E. K., and Rau, J. A.: Characteristics of atmospheric organic and elemental carbon particle concentrations in Los Angeles, Environ. Sci. Technol., 20, 580-589, doi:10.1021/es00148a006, 1986.

Harris, D. C.: Quantitative chemical analysis, 8th Edn., W.H. Freeman and Co., New York, 2010.

Hu, D., Bian, Q. J., Lau, A. K. H., and Yu, J. Z.: Source apportioning of primary and secondary organic carbon in summer $\mathrm{PM}_{2.5}$ in Hong Kong using positive matrix factorization of secondary and primary organic tracer data, J. Geophys. Res.-Atmos., 115, D16204, doi:10.1029/2009jd012498, 2010.

Hu, W. W., Hu, M., Deng, Z. Q., Xiao, R., Kondo, Y., Takegawa, N., Zhao, Y. J., Guo, S., and Zhang, Y. H.: The characteristics and origins of carbonaceous aerosol at a rural site of PRD in summer of 2006, Atmos. Chem. Phys., 12, 1811-1822, doi:10.5194/acp12-1811-2012, 2012. 
Huang, X. H. H., Bian, Q. J., Louie, P. K. K., and Yu, J. Z.: Contributions of vehicular carbonaceous aerosols to $\mathrm{PM}_{2.5}$ in a roadside environment in Hong Kong, Atmos. Chem. Phys., 14, 92799293, doi:10.5194/acp-14-9279-2014, 2014.

Lim, H. J. and Turpin, B. J.: Origins of primary and secondary organic aerosol in Atlanta: Results' of time-resolved measurements during the Atlanta supersite experiment, Environ. Sci. Technol., 36, 4489-4496, 2002.

Lin, P., Hu, M., Deng, Z., Slanina, J., Han, S., Kondo, Y., Takegawa, N., Miyazaki, Y., Zhao, Y., and Sugimoto, N.: Seasonal and diurnal variations of organic carbon in $\mathrm{PM}_{2.5}$ in Beijing and the estimation of secondary organic carbon, J. Geophys. Res.-Atmos., 114, D00G11, doi:10.1029/2008JD010902, 2009.

Malm, W. C., Schichtel, B. A., Pitchford, M. L., Ashbaugh, L. L., and Eldred, R. A.: Spatial and monthly trends in speciated fine particle concentration in the United States, J. Geophys. Res.Atmos., 109, D03306, doi:10.1029/2003jd003739, 2004.

Matsumoto, M. and Nishimura, T.: Mersenne twister: a 623dimensionally equidistributed uniform pseudo-random number generator, ACM Trans. Model. Comput. Simul., 8, 3-30, doi:10.1145/272991.272995, 1998.

Millet, D. B., Donahue, N. M., Pandis, S. N., Polidori, A., Stanier, C. O., Turpin, B. J., and Goldstein, A. H.: Atmospheric volatile organic compound measurements during the Pittsburgh Air Quality Study: Results, interpretation, and quantification of primary and secondary contributions, J. Geophys. Res.-Atmos., 110, D07S07, doi:10.1029/2004jd004601, 2005.

Pio, C., Cerqueira, M., Harrison, R. M., Nunes, T., Mirante, F., Alves, C., Oliveira, C., de la Campa, A. S., Artinano, B., and Matos, M.: OC / EC ratio observations in Europe: Rethinking the approach for apportionment between primary and secondary organic carbon, Atmos. Environ., 45, 6121-6132, doi:10.1016/j.atmosenv.2011.08.045, 2011.
Polidori, A., Turpin, B. J., Lim, H. J., Cabada, J. C., Subramanian, R., Pandis, S. N., and Robinson, A. L.: Local and regional secondary organic aerosol: Insights from a year of semi-continuous carbon measurements at Pittsburgh, Aerosol Sci. Tech., 40, 861872, 2006.

Robinson, A. L., Donahue, N. M., Shrivastava, M. K., Weitkamp, E. A., Sage, A. M., Grieshop, A. P., Lane, T. E., Pierce, J. R., and Pandis, S. N.: Rethinking Organic Aerosols: Semivolatile Emissions and Photochemical Aging, Science, 315, 1259-1262, doi:10.1126/science.1133061, 2007.

Saylor, R. D., Edgerton, E. S., and Hartsell, B. E.: Linear regression techniques for use in the EC tracer method of secondary organic aerosol estimation, Atmos. Environ., 40, 7546-7556, doi:10.1016/j.atmosenv.2006.07.018, 2006.

Turpin, B. J. and Huntzicker, J. J.: Secondary Formation of Organic Aerosol in the Los-Angeles Basin - a Descriptive Analysis of Organic and Elemental Carbon Concentrations, Atmos. Environ. A-Gen., 25, 207-215, 1991.

Turpin, B. J. and Huntzicker, J. J.: Identification of Secondary Organic Aerosol Episodes and Quantitation of Primary and Secondary Organic Aerosol Concentrations during Scaqs, Atmos. Environ., 29, 3527-3544, 1995.

Wang, Z., Wang, T., Guo, J., Gao, R., Xue, L. K., Zhang, J. M., Zhou, Y., Zhou, X. H., Zhang, Q. Z., and Wang, W. X.: Formation of secondary organic carbon and cloud impact on carbonaceous aerosols at Mount Tai, North China, Atmos. Environ., 46, 516527, 2012.

Yu, S. C., Dennis, R. L., Bhave, P. V., and Eder, B. K.: Primary and secondary organic aerosols over the United States: estimates on the basis of observed organic carbon (OC) and elemental carbon (EC), and air quality modeled primary OC / EC ratios, Atmos. Environ., 38, 5257-5268, doi:10.1016/j.atmosenv.2004.02.064, 2004. 